\title{
ELEMENTAL ANALYSIS OF PIGMENTS IN THE CERAMIC HUACO "THROAT-CUTTER WARRIOR WITH TROPHY” USING X-RAY FLUORESCENCE SPECTROSCOPY
}

\author{
C. LUIZAR OBREGON ${ }^{a^{*}}$, M.A. ZAMALLOA JARA ${ }^{b}$, K. CONTRERAS \\ $a^{*}$ Departamento Académico de Química, Facultad de Ciencias, Universidad Nacional de San Antonio Abad del Cusco, Cusco, Perú \\ ${ }^{b}$ Departamento Académico de Física, Facultad de Ciencias, Universidad Nacional de San Antonio Abad del Cusco, Cusco, Perú \\ 'Institut Langevin, Ecole Supérieure de Physique et Chimie Industrielle, Paris, France
}

\begin{abstract}
The X-ray fluorescence spectroscopy technique was used, with a portable equipment, to analyze traces of elements, in a ceramic piece, commonly called "huaco", identified as the "Throat-Cutter Warrior with Trophy", and related to the Moche Culture (between 100 and 800 years a.D.) that developed on Peru's north coast. The analysis has been made in the coatings of red, brown, orange and white color, in the matrix-paste and in the NIST2711a standard. In the ceramic piece, the presence of Iron was confirmed, in greater quantity, in the overlapped layers of red and brown color, while, in the white pigment, elements of Zinc and Barium were detected, considering that the latter never had been reported in Moche ceramic. In the areas corresponding to the eyes, of metallic aspect, $91 \%$ copper has been detected. It is argued that the similitude in iconography and materials would indicate that we are dealing with an ancient piece.
\end{abstract}

Keywords: ceramic, elemental analysis, huaco, Moche culture, pigments, pXRF.

\section{INTRODUCTION}

The Moche culture developed on the north coast of Peru, between the Lambayeque and Huarmey [1] rivers (Figure 1), approximately, between 100 and 800 years A.D. [2]. That culture has left great historical wealth, as well as an enigma about its disappearing, which is usually associated to climatic problems, with the "El Niño" phenomenon. One of its main characteristics is the fine ceramics [1,3-9], of impressive finish, among which the portrait huacos stand-out as high quality pottery pieces that display faces and Moche society's activities.

Moche ceramic has been studied by diverse authors, from the iconography of daily-use, ornamental and ritual vessels, up to their possible elaboration techniques $[1,4-7,10-19]$. There also are publications on raw materials used, and the pottery's chemical composition, that are oriented towards identifying political and economic patterns, as well as development stages of the Moche culture $[1,6,20]$.

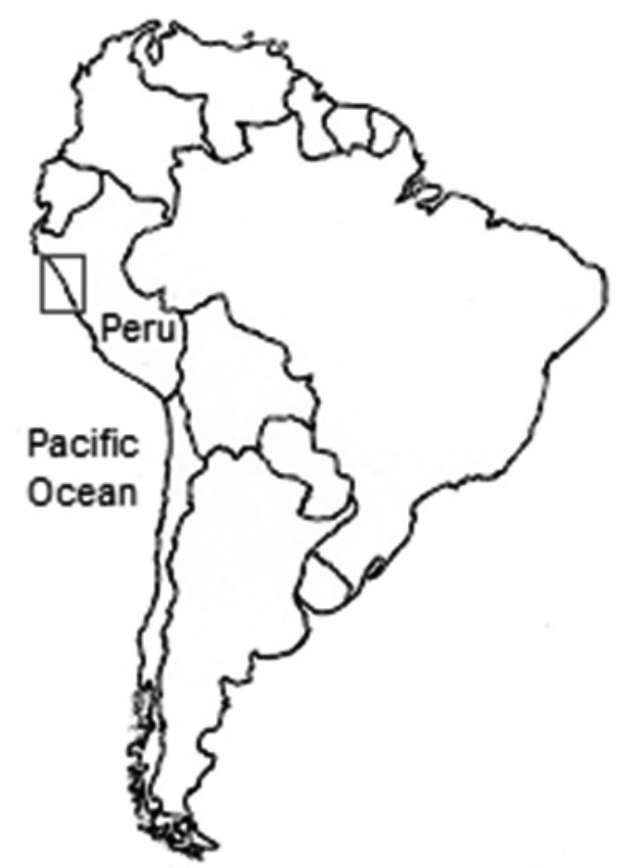

Figure 1. Moche culture's geographical localization map.
Rohtfrisch (2010) made observations with a sweep electronic microscope coupled-up with an X-ray spectroscope, in energy dispersion (EDS), and semiquantitative elemental analysis of fragments of ritual ceramics, managing to differentiate the paste, slip (engobe) and coating or paint. Furthermore, he identified the use of three types of matrix-pastes: white, red and black [9]. The white paste's clay matrix was characterized by presenting greater Calcium content than the others. However, he also confirmed that the white slip (engobe) presented a strong proportion of $\mathrm{SiO}_{2}, \mathrm{Al}_{2} \mathrm{O}_{3}, \mathrm{CaO}$. In the white coating, she suggested the possibility of the use of $\mathrm{CaSO}_{4}$, as charge, in a similar way to that found in the Huaca de la Luna's mural paintings. The red coatings presented less concentration of $\mathrm{CaO}(<10 \%)$ than the white slips [9], and in the fine line ceramics, the finish was mainly composed of $\mathrm{SiO}_{2}, \mathrm{Al}_{2} \mathrm{O}_{3}$ and $\mathrm{Fe}_{2} \mathrm{O}_{3}$, in probable combination with another clay, rich in Si and Al [9].

Del Solar (2016) used a hand-portable X-ray fluorescence equipment (pXRF), to evaluate fragments of bichrome and polychrome ceramic. He focused on the $\mathrm{K}, \mathrm{Ca}, \mathrm{Mn}, \mathrm{Fe}, \mathrm{Zn}, \mathrm{Ga}, \mathrm{As}, \mathrm{Rb}, \mathrm{Sr}$ and $\mathrm{Y}$ [21] elements, and found the presence of Calcium, in the ceramics' body, and that of $\mathrm{Zn}$, in all of them. The latter had not been previously reported. In addition, he found that the $\mathrm{Sr} / \mathrm{Fe}$ and $\mathrm{Rb} / \mathrm{Sr}$ intensity proportions could contribute to the Moche ceramics' classification. Nevertheless, the published studies on Moche portrait huacos $[3,4,6]$ are still oriented towards iconography, ethnography, style and time period they belonged to, probably, because their chemical analysis requires the use of either non-invasive or non-destructive techniques.

Among the non-destructive spectroscopic techniques used in the historical heritage chemical composition study, we can mention X-ray fluorescence (XRF), the X-ray dispersive energy (EDX), and the X-ray emission produced by protons (PIXE). The first is developed by seeking its components' minimization, without losing the analytical trustworthiness and sensibility, and there are diverse studies that show its broad application, in the study of volcanic rocks [22], rock art [23], environment and pollution [24], pigments [25-27], agronomy [28], obsidians [29], ceramics [30], post-mortem analysis [31] and others [32-34].

The trustworthiness and validity of the analytical results produced by handportable X-ray fluorescence equipment (pXRF) has been previously discussed $[35,36]$. Technological progress and the miniaturization of computers, multicanal analyzers, detectors, amplifiers and other electronic components does not seem to have influenced the XRF analytical quality. Furthermore, the results can be validated by external comparison with data obtained with other techniques, or through the use of standards [35]. Among the sources that increase error, the use of short analysis time stands-out, as well as the presence of the element of interest, in high concentrations, the presence of other elements, the nature of the matrix, the irradiated surface and depth and, as in all analytic technique, the operator. However, one of the advantages of $\mathrm{pXRF}$, in comparison to the other techniques that use X-rays, is that it can be used, without causing damage, on complete archaeological pieces of diverse sizes, and not only on fragments of cultural value.

In that sense, this work aims at identifying the pigments' constituting chemical elements that cover the "Throat-Cutter Warrior with Trophy" huaco (Figure 2), a complete piece, through X-ray fluorescence, a non-destructive and 
non-invasive technique, seeking similarities between the studied huaco, and other reported studies on Moche ceramic elemental analysis.

\section{EXPERIMENTAL}

The studied "Throat-Cutter Warrior with Trophy" huaco was kindly lent to the authors, by a private collector, for its on-site evaluation. It is known that the owner received the repaired piece around 2010, and that, up to this date, it hasn't gone through any other intervention. The body is made of clay, of approximately $44 \mathrm{~cm}$ in height (Figure 2). It is a small hollow and smoothened statue, representing a Moche warrior, holding a cutting weapon, in his right hand and, in the left, an individual's cut head.
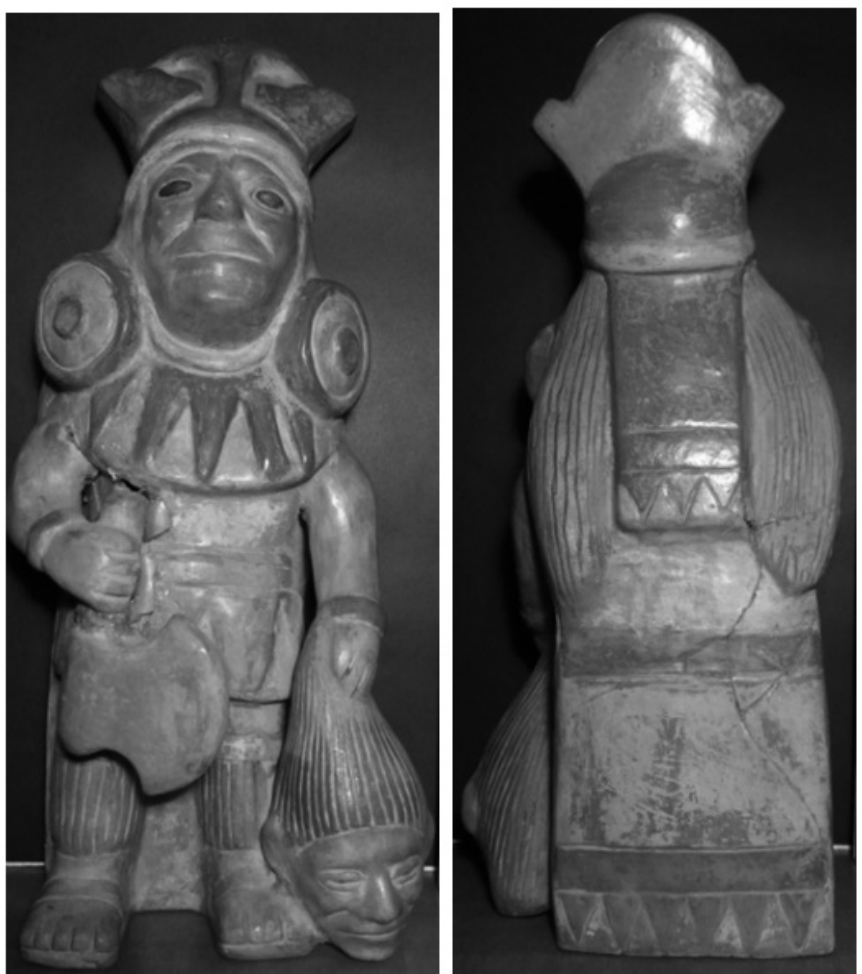

Figure 2. The "Throat-Cutter Warrior with Trophy". Cusco, Bonet Private Collection.

It isn't clear whether it is a sacrifice, the representation of the end of a battle, or that of the ego's death, indicating that the initiate, on his way to selfrealization, has reached the rank of Master, after having vanquished his inner demons, in a personal struggle. The piece reveals similarities with other Moche culture representations, in ceramic and metal and, besides, it presents brown, red, orange and white tonalities. The eyes' style coincides with the shapes described by Erell Hubert [19], of the pre-Incan Moche culture, although they stand-out for being small elliptical metallic incrustations of about $1.5 \mathrm{inch}$, in their longest diameter.
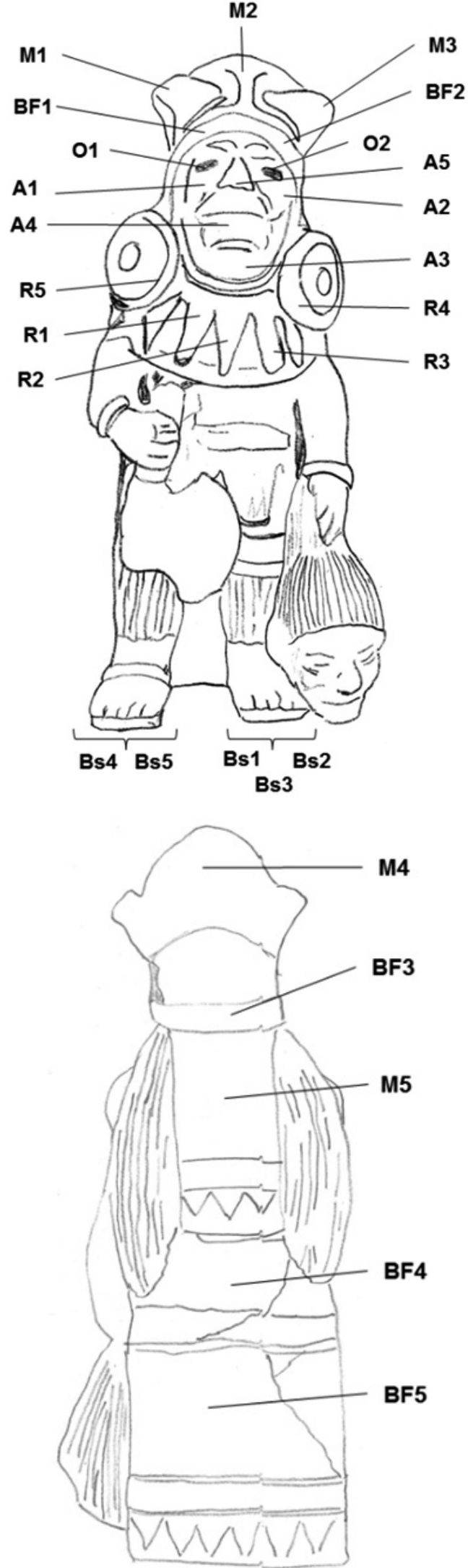

Figure 3. The "Throat-Cutter Warrior with Trophy" huaco. Front and reverse sides' analysis points. $\mathrm{R}=$ red, $\mathrm{A}=$ orange, $\mathrm{M}=$ brown, $\mathrm{BF}=$ fugitive white, $\mathrm{Bs}=$ matrix-paste, $\mathrm{O}=$ metallic eyes (Drawing made by the authors). 
The analysis was performed as in laboratory conditions, and the sample was manipulated with gloves. 25 analysis points were chosen, as much on the front, as on the back side (Figure 3). They were codified, according to each pigment's color: red (R1, R2, R3, R4 and R5), brown (M1, M2, M3, M4 and M5), orange (A1, A2, A3, A4 and A5), white (BF1, BF2, BF3, BF4 and BF5) and matrix-paste (Bs1, Bs2, Bs3, Bs4 and Bs5). Two points were analyzed in the eyes (O1 and $\mathbf{O 2}$ ).

For the elemental analysis, a Delta-Premium Olympus handheld portable $\mathrm{X}$-ray fluorescence spectroscopy equipment (pXRF) was used in two operation modes: Soil and Geochem. The Geochem operation mode allows identifying light elements as $\mathrm{Mg}, \mathrm{Al}, \mathrm{Si}$, and $\mathrm{S}$.

The equipment possesses an Rh X-ray tube, and a detector of Silicon Drift SDD type. It also has a mini camera DP-6000-CC through which a circle with a diameter of $8 \mathrm{~mm}$ is observed, which in turn corresponds to the area to be irradiated To maintain an analysis geometry as fixed as possible, the piece was placed horizontally on a cloth on a table and on top of it was supported the analysis surface of the detector (shooting window), keeping as much contact as possible with the sample during the time of analysis.

The elements' identification was obtained by using the Innov X-Delta software, the concentration reports (ppm) of which were then processed on Excel data sheets. Averages are presented of five measurements performed on each color area, being that, each measurement includes three or two beams, with energies from 0 to $40 \mathrm{KeV}$, detailed in Table 1 . The presence of each element was confirmed for those cases in which the XRF spectrum showed the respective emission lines of the element.

In parallel, five measurements were performed on the NIST2711 a reference material, in equal conditions as for the color areas, where the reported values correspond to the average values.

Table 1. Experimental conditions used.

\begin{tabular}{|c|c|c|c|}
\hline \multicolumn{4}{|c|}{ Soil Operation Mode } \\
\hline Beam & Energy / KeV & Real Time / s & Tube Current Set $\mu \mathbf{A}$ \\
\hline 1 & $1-40$ & 30 & 67.1 \\
\hline 2 & $2-40$ & 30 & 34.0 \\
\hline 3 & $3-15$ & 50 & 78.5 \\
\hline \multicolumn{5}{|c|}{ Geochem Operation Mode } \\
\hline \multicolumn{5}{|c|}{ Total } & 20 & 99.9 \\
\hline 2 & $1-40$ & 40 & 200 \\
\hline & $2-10$ & 80 & \\
\hline
\end{tabular}

\section{RESULTS AND DISCUSSION}

3.1. Fugitive White (BF)

The white coating, with light yellow tonality, was denominated "fugitive white" (BF), since this is the way archeologists call the white pigment that darkens, with time, or acquires a yellow tonality [37]. The elemental analysis' results reveal that $\mathrm{BF}$ coating presents Zinc and Barium, in addition to Calcium, given that it would be linked to the presence of $\mathrm{CaCO}_{3}, \mathrm{ZnO}_{2}$ and/or $\mathrm{BaSO}_{4}$ (Table 2).

The presence of Calcium, in the elaboration of white coatings, in ceramics, is related to kaolin or kaolinite $\left(2 \mathrm{SiO}_{2} \cdot \mathrm{Al}_{2} \mathrm{O}_{3} \cdot 2 \mathrm{H}_{2} \mathrm{O}\right)$, calcium carbonate $\left(\mathrm{CaCO}_{3}\right)$, plaster or calcium sulfate $\left(\mathrm{CaSO}_{4}\right)$, calcareous clays, mollusks' valves, and birds' eggshells. Usually, kaolinite loses its whitish color, when it contains organic impurities, which would explain the "fugitive white" denomination for that coating. Furthermore, phosphorous could contribute to explain the white color, since it is present in composed elements, such as hydroxyapatite $\left(\mathrm{Ca}_{5}(\mathrm{PO})\right)$ proceeding from bones of diverse origins [38]. Upon comparing the Calcium content (Table 2), between the orange (98435 ppm), red (90882 ppm), fugitive white (89977), brown (52751 ppm) and matrix-paste (52607 ppm) colored pigments, one observes that the BF contains less Calcium than the orange and red, in such a way that Calcium would not be the only origin of the whitish coating.

By using the PIXE technique, on Moche culture vessels, Swam and col. (1999) found that variability can exist, in the origin of the white color used by the Moche [1]. Among the vases decorated with white pigments, they studied one that presented high Manganese content, others, Titanium, and a third one
Phosphorous.

In the results obtained with the Moche portrait huaco (Table 2), the BF presents $14823 \mathrm{ppm}$ of $\mathrm{Zn}$, meanwhile the other pigments don't go over 589 ppm (red). The presence of Zinc, in Moche ceramic fragments, has already been recently reported [21]. In ceramics, Zinc oxide produces certain white flashes, and affects the color of a coating's other constituting elements [39]. The use of zinc white $(\mathrm{ZnO})$, in watercolors and oil paints, was much spread after the year of 1800 , when its good behavior, as a pigment, was discovered, as it was soluble in oil. However, the presence of organic material provokes the coating's "yellowing" and loss of brilliance.

On the market, there is lithopone, a mixture of zinc sulfur and barium sulfate, which is another white pigment used by artists, in oil paints and canvas, along with an organic agglutinating agent. The identification of the nature of a possible component of that type, in the studied huaco, requires the use of other techniques, such as Fourier's Transformed Infrared Spectroscopy (known as FTIR,) that focus on possible organic constituting elements, as much as possible, in a non-destructive way.

Table 2. Elemental composition of pigments (ppm) in Soil mode presented as: majority, medium, and minority elements.

\begin{tabular}{|c|c|c|c|c|c|c|c|}
\hline \multirow{2}{*}{\multicolumn{2}{|c|}{ Element }} & \multicolumn{5}{|c|}{ 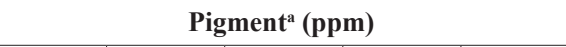 } & \multirow{2}{*}{$\begin{array}{l}\text { bNIST } \\
2711 a\end{array}$} \\
\hline & & $\mathbf{R}$ & A & M & BF & Bs & \\
\hline \multicolumn{8}{|c|}{ Majority elements } \\
\hline \multirow[t]{2}{*}{$\mathbf{S}$} & & 94696 & 109550 & 14085 & 79632 & 12109 & 2390 \\
\hline & \pm & 6490 & 12089 & 1013 & 9102 & 759 & 128 \\
\hline \multirow[t]{2}{*}{$\mathrm{Cl}$} & & 521 & 811 & 612 & 1487 & 1178 & 138 \\
\hline & \pm & 39 & 38 & 61 & 151 & 114 & 21 \\
\hline \multirow[t]{2}{*}{$\mathbf{K}$} & & 34835 & 39992 & 32072 & 27732 & 42496 & 27514 \\
\hline & \pm & 4305 & 2541 & 61 & 151 & 114 & 333 \\
\hline \multirow[t]{2}{*}{$\mathrm{Ca}$} & & 90882 & 98435 & 52751 & 89977 & 52607 & 27272 \\
\hline & \pm & 2180 & 3157 & 1544 & 5806 & 2888 & 333 \\
\hline $\mathbf{B a}^{\mathrm{c}}$ & & 6116 & 5286 & 5117 & 26983 & 4452 & 7345 \\
\hline \multirow[t]{2}{*}{$\mathbf{F e}$} & & 62251 & 44469 & 96281 & 26423 & 44192 & 24005 \\
\hline & \pm & 4210 & 2046 & 10869 & 1358 & 270 & 145 \\
\hline \multirow[t]{2}{*}{$\mathrm{Zn}$} & & 589 & 181 & 266 & 14823 & 225 & 369 \\
\hline & \pm & 4 & 4 & 10 & 1765 & 3 & 5 \\
\hline \multicolumn{8}{|c|}{ Medium elements } \\
\hline Mn & & $572 \pm 31$ & $734 \pm 33$ & $487 \pm 36$ & $487 \pm 36$ & $793 \pm 8$ & $641 \pm 8$ \\
\hline $\mathbf{Z r}$ & & $289 \pm 32$ & $295 \pm 39$ & $244 \pm 13$ & $283 \pm 12$ & $293 \pm 10$ & $403 \pm 5$ \\
\hline $\mathrm{Sr}$ & & $346 \pm 13$ & $333 \pm 20$ & $336 \pm 16$ & $401 \pm 45$ & $320 \pm 2$ & $234 \pm 5$ \\
\hline $\mathbf{R b}$ & & $107 \pm 4$ & $118 \pm 6$ & $117 \pm 5$ & $104 \pm 4$ & $114 \pm 1$ & $121 \pm 1$ \\
\hline $\mathrm{Cu}$ & & $86 \pm 13$ & $240 \pm 46$ & $91 \pm 2$ & $62 \pm 1$ & $66 \pm 2$ & $23 \pm 1$ \\
\hline \multicolumn{8}{|c|}{ Minority elements } \\
\hline $\mathrm{Cr}$ & & $25 \pm 0$ & - & - & $356 \pm 27$ & - & . \\
\hline As & & $37 \pm 3$ & $43 \pm 1$ & $47 \pm 5$ & $36 \pm 7$ & $44 \pm 1$ & $123 \pm 4$ \\
\hline Th & & $72 \pm 11$ & $65 \pm 15$ & $57 \pm 12$ & $63 \pm 10$ & $89 \pm 2$ & $77 \pm 7$ \\
\hline $\mathbf{Y}$ & & $22 \pm 2$ & $24 \pm 2$ & $18 \pm 1$ & $23 \pm 1$ & $23 \pm 1$ & $35 \pm 2$ \\
\hline $\mathrm{Nb}$ & & $13 \pm 2$ & $13 \pm 2$ & $10 \pm 2$ & $15 \pm 1$ & $13 \pm 0$ & $24 \pm 1$ \\
\hline $\mathbf{P b}$ & & $36 \pm 2$ & $42 \pm 5$ & $52 \pm 3$ & $36 \pm 3$ & $41 \pm 1$ & $1314 \pm 10$ \\
\hline $\mathbf{N i}$ & & $22 \pm 2$ & $34 \pm 4$ & - & $25 \pm 6$ & $18 \pm 2$ & $24005 \pm 145$ \\
\hline
\end{tabular}

a Pigments $\mathrm{R}=$ red; $\mathrm{A}=$ orange $\mathrm{M}=$ Brown; $\mathrm{BF}=$ Fugitive white $; \mathrm{Bs}=$ matrix-paste.

${ }^{\mathrm{b}}$ It corresponds to 5 repetitions; ${ }^{\mathrm{c}}$ Detected only one time between 5 repetitions.

${ }^{\mathrm{c}}$ Counts/s in L $\alpha$ for Calcium (4.47 KeV), beam 3, point 1 for each color. 
The fugitive white coating's XRF spectrum (Figure 4) shows emission spectral lines in $4.47 \mathrm{KeV}$ and $4.83 \mathrm{KeV}$, corresponding to $\mathrm{L}_{\alpha}$ and $\mathrm{L}_{\beta}$ of Barium. Therefore, it could be suggested that another causing factor of its white color would be $\mathrm{BaSO}_{4}$. In 2010, Wright reported the finding of barium sulfate crystals (barite or heavy spar), as part of the support, in the Sipán funerary platform's mural paintings, in the Lambayeque Valley, where the Moche culture developed, reason for which its use in pottery is not to be discarded.

From literature, it is known that, in Europe, the $\mathrm{TiO}_{2}$ was used as a constituting element of pigments, since the beginning of the $17^{\text {th }}$ century. This means that, if the piece were from the Moche culture's time, Ti ought not to be present, unless it is a contemporaneous piece, or that it might be present in small proportions. However, there is the possibility that, in Peru, $\mathrm{TiO}_{2}$ was used, before the Spaniards' arrival, above all, because, in 2013, the presence of titanium minerals was reported in the Peruvian South and, especially, illmenito $\left(\mathrm{FeTiO}_{3}\right)$ and rutile $\left(\mathrm{TiO}_{2}\right)$, with the presence of $\mathrm{Zr}$ as frequent impurity in titanium minerals.

The contemporaneous commercial rutile pigments may contain $\mathrm{Si}, \mathrm{Al}$ and $\mathrm{Zr}$, and are used as coatings, among other applications, given their refrigerating photo-catalytic properties, which could justify their use in the confection of jars, vessels and other ceramics. However, the titanium's emissions, the main spectral lines of which are $\mathrm{K}_{\alpha}$ in $4.51 \mathrm{KeV}$ and $\mathrm{K}_{\beta}$ in $4.93 \mathrm{KeV}$, do not appear in the spectrum of $\mathbf{B F}$.

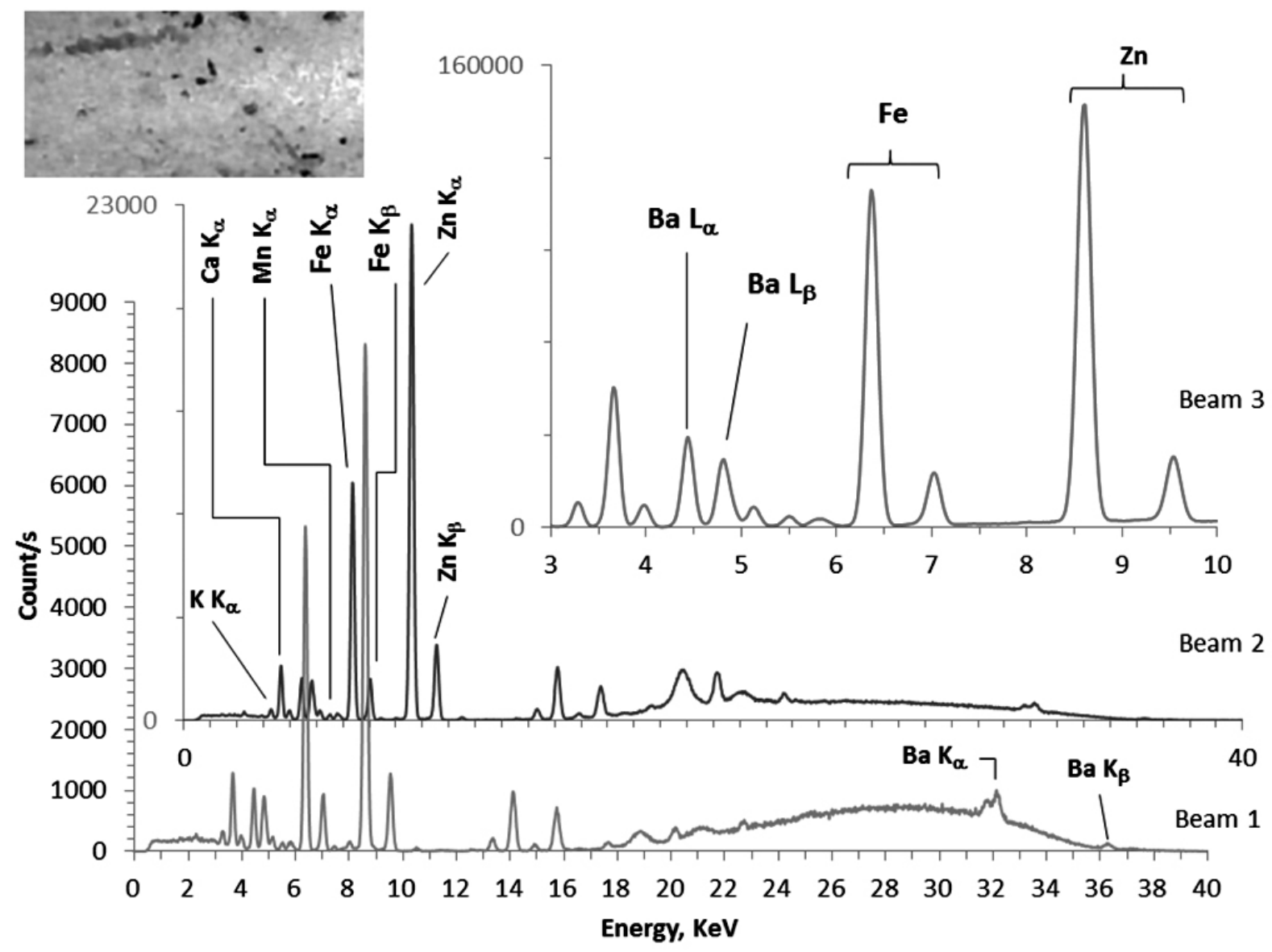

Figure 4. XRF spectrum, Soil mode, beam 1, of the fugitive white coating (BF1), and 200X image blow-up.

\subsection{Red, Orange and Brown}

In general, the main element linked to red, brown and, even black pigment are Iron, although the brown and reddish brown colors can also be related to chrome or zinc oxides, and the reds, with carmine or Tin. In the study on Moche vessels conducted by Swam and collaborators (1999), the red, pink and black coatings presented a similar composition among themselves, and all were rich in Iron. They suggested that the red coating, of an abnormal piece, could be due to the use of bone ashes, rich in Phosphorous, and the pink color, to a mixture between the red and white pigments [1].

Furthermore, diverse studies have agreed that during the elaboration of ceramics, the Moche performed a slip (engobe) stage, in which they would put the piece in contact with a material rich in Calcium, thus giving it a white color. Then, directly after the paling, a fine finish was applied, with the desired color pigments that, sometimes, were agglutinated to the matrix-paste's clay $[40,41]$

Given the characteristics of the pXRF equipment, it is not possible to know the radiation's exact penetration depth, on the sample and, therefore, one cannot categorically affirm that the results obtained only represent the coating, or if they also include the slip (engobe) or matrix-paste. Besides, the pigments are not homogeneously distributed on the surface, since there are inherent cracks and wear, due to bad manipulation or antiquity. In Figure 5, the worn-out zones appear to reveal the presence of whitish slip (engobe), with green tones. Nevertheless, the size of the cracks is too small to focus the pXRF equipment's $\mathrm{X}$ radiation beam, and to obtain a representative reading.

In Figure 5, the spectrums are shown of three red, orange and brown coatings. They are very similar in elemental composition (Table 2), and are differentiated by the Zinc's K $\alpha$ line's intensity. 


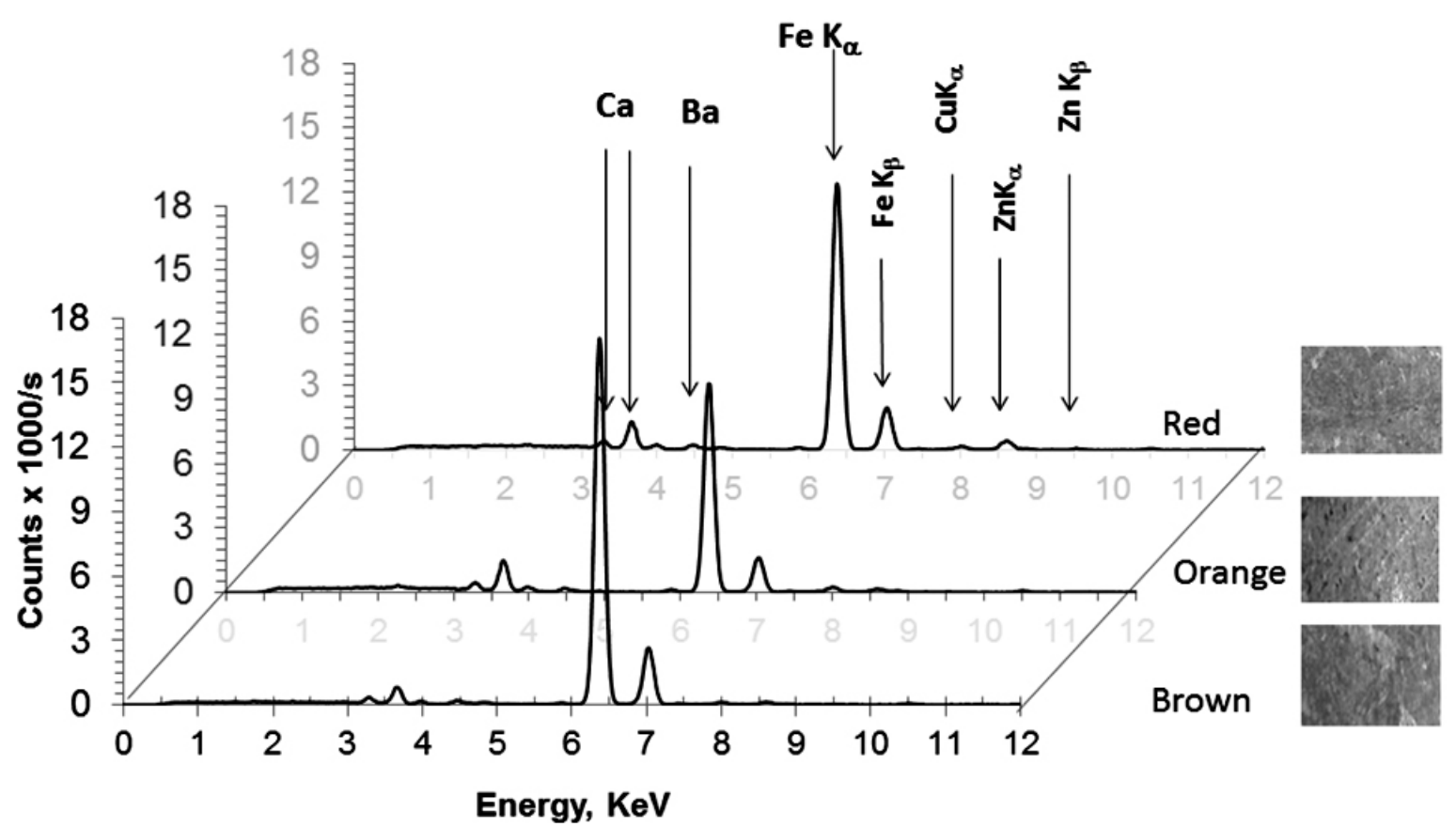

Figure 5. XRF spectrums, Soil mode, beam 1 of the red, orange and brown pigments and 200X image blow-up.

These coatings are mainly constituted of iron oxides, most probably, in the form of hematite $\left(\mathrm{Fe}_{2} \mathrm{O}_{3}\right)$. The result of the elemental analysis, in Geochem mode (Figure 6), coincides with that of the Soil mode.

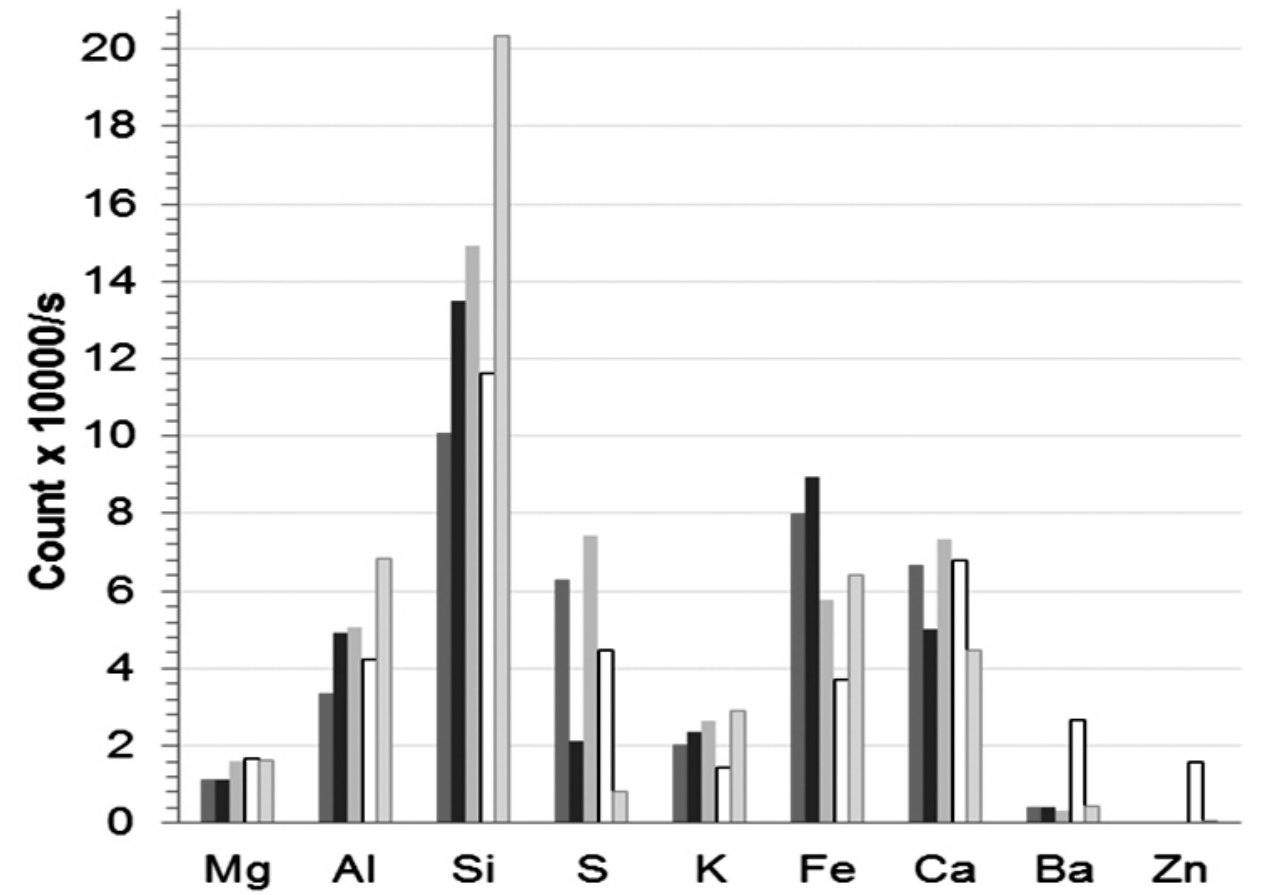

Figure 6. Comparison of the pXRF elemental analysis of red (red), brown (brown), orange (yellow), white fugitive (white) and matrix-paste (pink), in Geochem mode.

The values presented for Iron (Table 2) confirm that this element is part of the matrix-paste. The variation between color coatings, can be attributed to the use of different proportions: matrix-paste and Iron pigment.

The orange pigment (Figure 6) shows greater Calcium and lesser Iron content than the red and brown pigments, which would confirm the combination of hematite, goethite or limonite with kaolin, to obtain the orange color, in the same way as reported by Ottalango (2015). Greater lead content is also observed, than in the red and BF pigments (Table 2), and the absence of cinnabar $(\mathrm{HgS})$.

In the brown pigment, the smaller proportion of sulfur stands-out, perhaps, due to the use of less Calcium or barium sulfate (Figure 6).

On the other hand, the high Silicon $(203381 \pm 8507)$ ppm and Aluminum 
$(68586 \pm 6629) \mathrm{ppm}$ concentrations, in the matrix-paste, identified in the Geochem mode (Figure 6), indicate that it contains aluminum-silicates, which is usual in clays and pigment mixtures[38].

The results of the NIST2711a standard, in Soil mode, allows to see the precision and exactitude (Table 3). The Titanium and Mercury were detected only in the standard and do not in the coatings.

Besides, the eyes, of metallic aspect, revealed to be mainly composed of Copper (91\%), Zinc (1.6\%) and Aluminum (1.5\%), and traces of Fe, Zr, Cr, $\mathrm{Nb}, \mathrm{Mo}, \mathrm{Bi}, \mathrm{Pb}$ and $\mathrm{Sr}$.

Table 3. Experimental and certificate values for elements in NIST2711a standard, Soil mode.

\begin{tabular}{|c|c|c|c|c|c|}
\hline \multirow{2}{*}{ Element } & \multicolumn{2}{|c|}{$\begin{array}{c}\text { Experimental } \\
\text { value, ppm }\end{array}$} & \multicolumn{2}{c|}{$\begin{array}{c}\text { Certificate value, } \\
\text { ppm }\end{array}$} & Relative Error \\
\cline { 2 - 6 } & Average & \pm & Average & \pm & $\left(\mathrm{X}_{\mathrm{M}}-\mathrm{X}_{\mathrm{T}}\right) / \mathrm{X}_{\mathrm{T}} * 100$ \\
\hline $\mathbf{K}$ & 27514 & 333 & 25300 & 1000 & 8.8 \\
\hline $\mathbf{C a}$ & 27272 & 228 & 24200 & 600 & 12.7 \\
\hline $\mathbf{F e}$ & 24005 & 145 & 28200 & 400 & -14.9 \\
\hline $\mathbf{P}$ & 5222 & 452 & 842 & 11 & 520.2 \\
\hline $\mathbf{T i}$ & 3174 & 37 & 3170 & 80 & 0.1 \\
\hline $\mathbf{P b}$ & 1314 & 10 & 1400 & 10 & -6.2 \\
\hline $\mathbf{M n}$ & 641 & 8 & 675 & 18 & -5.0 \\
\hline $\mathbf{Z n}$ & 369 & 5 & 414 & 11 & -10.8 \\
\hline Sr & 234 & 5 & 242 & 10 & -3.2 \\
\hline $\mathbf{A s}$ & 123 & 4 & 107 & 5 & 14.8 \\
\hline $\mathbf{C u}$ & 123 & 3 & 140 & 2 & -12.0 \\
\hline $\mathbf{V}$ & 90 & 1 & 81 & 6 & 12.0 \\
\hline $\mathbf{C r}$ & 38 & 0 & 52 & 3 & -27.0 \\
\hline $\mathbf{N i}$ & 23 & 1 & 22 & 1 & 4.8 \\
\hline $\mathbf{H g}$ & 10 & 1 & 7 & 0 & 34.8 \\
\hline
\end{tabular}

\section{CONCLUSIONS}

The comparison between the results obtained in this study, with those published by other researchers, is difficult to establish, not only because the clays used in the fabrication could have different origins, but, also, because the pieces could belong or correspond to different time periods, elaboration workshops, places where they were found and other factors

Regarding the origin of the piece, on the basis of similarities found in the iconography, the curious presence of Barium, and the use of materials simila to those of the ancient Moche culture, we could suggest that it might be a piece of genuine antiquity and with cultural value. The use of Iron oxides, the combination of the matrix-paste, with other pigments, to obtain colors and tonalities (red, orange and brown) that characterize pieces from that Northern Peruvian culture, and the presence of Zinc, coincide with the literature. The presence of Barium stands-out in the fugitive white pigment that had not been previously reported in Moche huaco portrait, although it was found in the Sipán mural paintings, which motivates us to continue studying the "Throat-Cutter Warrior with Trophy" portrait huaco.

However, it is still premature to affirm that we are dealing with an ancient piece, elaborated by the Moche culture (100 to 800 years a.D.). Even when considering the absence of Titanium, an element introduced as $\mathrm{TiO}_{2}$ in the artist media after 17 th.

In addition, we must consider that it is not possible to perform a destructive dating analysis, and we don't have samples linked to an excavation proceeding context. Neither is it possible to introduce the huaco into an electronic microscope, due to its size, to thus explore its baking conditions or crystalline shapes. So, there would still be the possibility of performing an element trace analysis, in parallel with other huaco ceramic samples, the characteristics of which are similar, and the Pre-Incan Moche origin of which has been previously confirmed, allowing the elaboration of a database, to make a more precise and trustworthy comparison. In turn, an analysis, based on the FTIR infrared spectroscopy, could be useful, especially, to evaluate the possible presence of organic agglutinating agents.

\section{ACKNOWLEDGMENTS}

The authors are grateful for the funding of the Vice-Rectorate of Research of UNSAAC, through the canon funds and the EPICENTRO project.

\section{REFERENCES}

1. C.P. Swann, S. Caspi, J. Carlson, Nucl Instrum Meth B, 1999, 150, 571

2. C. Chapdelaine, J. Archaeol Res Research, 2011, 19, 191.

3. E.P. Benson, INDIANA, 1984, 9, 367.

4. E.P. Benson, Metropol. Museum J., 1983, 18, 39

5. W.E. Brooks et al., Bulletin de l'Institut français d'études andines, 2008, 441.

6. R.F. Canalis, L. Cino, Otol. Neurotol., 2003, 24, 828

7. Castillo Butters, L.J., De Cupisnique a los Incas: El Arte del valley de Jequetepeque, 2009, 208.

8. J. Gamboa Velasquez, B. Mus. Chil. Arte Prec., 2013, 18, 9.

9. A. Rohfritsch, Bull. de l'Institut français d'études andines, 2010, 389.

10 H. Tschopik, Am. Antiquity, 1950, 15, 196.

11. H. Bernier, Estud. Atacameños, 2009, 157.

12. Castillo Butters, L.J., Programa Arqueológico San José de Moro. Informe de Excavaciones. Temporada 2006. Pontificia Universidad Católica del Perú, 2006, 256.

13. H. Bernier, Lat. Am. Antiq., 2010, 21, 22

14. J. Kaplan, Ceramics: Art and Perception, 2011, 85, 6.

15. L.A. Parsons, Am. Antiq., 1962, 27, 515.

16. Bruker, Table of energies, 2016

17. S. Uceda, R. Morales, C. Rengifo, Excavaciones en la Ladera Oeste de Cerro Blanco. 2015

18. E.M. Cole, Moche Marks of Distinction: Time and Politics in Painted Pottery Substyles of the Moche Culture, North Coast, Peru AD 100-900. UCLA. Tesis. 2012.

19. E. Hubert, J. Anthropol. Archaeol., 2016, 44, 1

20. C. Chapdelaine, G. Kennedy, S. Uceda, Bulletin de l'Institut français d'études andines, 1995, 24, 183 .

21. N. Del-Solar-Velarde et al., Heritage Science, 2016, 4, 37.

22. A.E. Steiner, R.M. Conrey, J.A. Wolff, Chem. Geol., 2017, 453, 35.

23. M. Sepulveda et al., J. Chil. Chem. Soc., 2015, 60, 2822.

24. M. Rouillon, M.P. Taylor, Environ. Pollut., 2016, 214, 255.

25. T.D. Chaplin et al., Phil. Trans. R. Soc. A, 2016, 374, 20160043.

26. M.S. Blonski, C.R. Appoloni, Appl. Radiat. Isotopes, 2014, 89, 47.

27. M. Sepúlveda et al., J. Chil. Chem. Soc., 2013, 58, 1836.

28. D.C. Weindorf, N. Bakr, Y. Zhu, Advances in Agronomy. Advances in Portable X-ray Fluorescence (PXRF) for envionmental, pedologival, and agronomic applications. Academic Press, 2014, 128.

29. M. Milić, J. Archaeol. Sci., 2014, 41, 285.

30. D. Ioannides et al., J. Archaeol. Sci.: Reports, 2016, 7, 554

31. A. Galli, L. Bonizzoni, X-Ray Spectrom., 2014, 43, 22

32. F. Lopes et al., X-Ray Spectrom., 2016, 45, 344

33. F. Lopes et al., J. Spectrosc., 2016, 2016, 1.

34 M. West et al., J. Anal. At. Spectrom., 2015, 30, 1839.

35. R.J. Speakman, M.S. Shackley, J. Archaeol. Sci., 2013, 40, 1435.

36. N. Goodale et al., J. Archaeol. Sci., 2012, 39, 875.

37. G. P. Bonnett, Oral communication, 2016.

38. F.V. Ottalagano, S.A. Domínguez, P.B. Bozzano, B. Mus. Chil. Arte Prec., 2015, 20, 57.

39. R.S. Popelka-Filcoff et al., J. Radioan. Nucl. Ch., 2007, 272, 17.

40. A. Rohfritsch, Bulletin de l'Institut français d'études andines, 2010, 389.

41. V. Wright, Bulletin de l'Institut français d'études andines, 2010, 299. 